\title{
The Effects of Past Hurricane Experiences on Evacuation Intentions through Risk Perception and Efficacy Beliefs: A Mediation Analysis $\mathscr{O}$
}

\author{
Julie L. Demuth, Rebecca E. Morss, And JefFrey K. LAZO \\ National Center for Atmospheric Research, ${ }^{\text {a }}$ Boulder, Colorado \\ CRAIG TRUMBO \\ Colorado State University, Fort Collins, Colorado
}

(Manuscript received 8 December 2015, in final form 5 May 2016)

\begin{abstract}
Individuals' past experiences with a hazard can encompass many different aspects, which can influence how they judge and respond to a future hurricane risk. This study, which utilizes survey data from coastal residents who are at risk from hurricanes, adds to understanding of past hazard experience in two ways. First, it examines six different aspects of people's past hurricane experiences and the relationships among them. Then, it draws on risk theories of behavioral responses to explore how these different experiences influence people's evacuation intentions for a hypothetical hurricane as mediated through multiple dimensions of risk perception (cognitive, negative affective) and efficacy beliefs (self efficacy, response efficacy). The results suggest that people can experience emotional or otherwise severe impacts from a hurricane even if they do not have experiences with evacuation, property damage, or financial loss. The results also reveal that different past hurricane experiences operated through different combinations of mediating variables to influence evacuation intentions. Some of these processes enhanced intentions; for instance, experience with evacuation, financial loss, or emotional impacts heightened negative affective risk perceptions, which increased evacuation intentions. Other processes dampened evacuation intentions; for instance, people with past hurricane-related emotional impacts had lower self efficacy, which decreased evacuation intentions. In some cases, these enhancing and dampening processes competed. Exploring people's different past weather experiences and the mechanisms by which they can influence future behaviors is important for more deeply understanding populations at risk and how they respond to weather threats.
\end{abstract}

\section{Introduction}

The atmosphere has little long-term memory of past hurricanes that have affected an area, but people do. Indeed, people's past experiences with a hazard are important for shaping how they recognize and develop judgments about a future risk, which can influence their responses to the threat (Weinstein 1989; Renn 2008;

Supplemental information related to this paper is available at the Journals Online website: http://dx.doi.org/10.1175/ WCAS-D-15-0074.s1.

${ }^{a}$ The National Center for Atmospheric Research is sponsored by the National Science Foundation.

Corresponding author address: Julie L. Demuth, NCAR, P.O. Box 3000, Boulder, CO 80307.

E-mail: jdemuth@ucar.edu
Wachinger et al. 2013). Past experience therefore is commonly measured in studies of risks, including weather hazards such as hurricanes (Weinstein 1989; Lindell 2012; Kellens et al. 2013; Huang et al. 2016). However, researchers who quantitatively analyze the role of past experiences in affecting future decisionmaking typically do so by treating experience as a variable to be controlled for rather than one that is inherently interesting. This tendency occurs across risk contexts, including in studies of hurricanes and other weather risks [see Demuth (2015) for a review].

As a result, most previous quantitative empirical investigations of past hurricane experience have two major limitations. First, the ways that most researchers measure experience tends to limit the ability to understand its role, either because the measurement items are so broad that is it unclear what is being measured or because multiple items are combined into one scale. 
People's past experiences with a hurricane can encompass many different aspects, and it is important to better understand these nuances and their influences. Multiple scholars therefore have noted the insufficient ways that people's past experiences with hazards (hurricanes and otherwise) have been measured in the existing literature, and they have identified the need to more thoughtfully study this concept (Weinstein 1989; Baker 1991; Lindell 2012; Kellens et al. 2013). Second, most previous studies focus only on whether past hurricane experience is related to future evacuation decisions by examining if a relationship exists and if it is positive or negative. Yet, it is also important to understand how past experience has an effect on a future behavior by examining the processes by which intervening variables may mediate the relationship (Hayes 2009, 2013). Lindell (2012) noted the need for mediation analyses generally in the context of disaster studies. Specific to studies of personal experience, Weinstein $(1989$, p. 47) noted that they "will be most informative if they include measurements of the variables thought to mediate the effects of experience." Because major gaps exist in current understanding of what experience represents and how it influences responses to future threats, we examine these topics here in the context of hurricanes.

The goal of this article is to contribute to foundational knowledge about what characteristics individuals bring into a risk situation, with a focus here on their experiences, and about the processes by which these experiences can affect their risk judgments and responses. This understanding can guide future research by informing theoretical avenues and methodological approaches to further investigate the nature and roles of experience as well as other constructs relevant to hazards. It can also help guide studies of risk communication that could be designed to enhance protective decision-making for hurricane risks.

We explore these topics using data from a survey of Miami-Dade County, Florida, residents who live along the coast and thus are likely to have past experiences with hurricanes and are at risk of future hurricanes. Respondents were asked about six different past hurricane experiences: experience with evacuation, property damage, financial losses, injury or death, emotional impacts or personal distress, and overall severity of impacts from hurricanes. Later in the survey, respondents were presented with a hypothetical scenario of a hurricane threatening landfall near Miami. Respondents then were asked, based on that information, about their likelihood of evacuating. Drawing on theories of behavioral responses to risks, respondents also were asked about their risk perceptions regarding the hurricane threat as well as their efficacy beliefs regarding responding to the threat. We use these data from at-risk coastal residents to investigate 1) characteristics of their past hurricane experiences, including the distribution of and relationships among the six aspects of experience measured here, and 2) for each different experience, how its effect on hypothetical evacuation intention might be mediated by risk perception and efficacy beliefs.

Section 2 briefly reviews how past hurricane experience has been studied empirically, including how it is typically measured and whether it has been shown to relate to evacuation behaviors. This section also discusses the risk theories that underpin the variables we investigate here as mediators of evacuation intentions. Section 3 describes our methods, including the survey sampling, implementation, design, and measures, as well as the regression-based mediation analysis employed here. Section 4 presents the distribution of and relationships among the six past hurricane experiences we measured, and section 5 provides the mediation analysis results. The key findings are summarized and their implications discussed in section 6 .

\section{Background}

\section{a. Conceptualizing and measuring past hurricane experience}

There are two common survey-based approaches that researchers employ to measure past hurricane experience. One approach is with questions that attempt to be all-encompassing by measuring, for example, the existence or amount of experience one has (e.g., "Have you experienced a hurricane?"; "Have you been personally affected by a past hurricane?"; "How many hurricanes have you experienced?") (e.g., Lindell et al. 2005; Peacock et al. 2005; Arlikatti et al. 2006; Lazo et al. 2010; Matyas et al. 2011). However, such questions are imprecise in what is being asked and consequently in what people are thinking about and what is being measured with their responses. For instance, in the case of Hurricane Katrina, someone who lived far from New Orleans and closely followed news coverage of the hurricane and of the people who were directly affected by it (e.g., in the Superdome, on rooftops) might consider themselves as having experienced Katrina. That experience, although important, differs considerably from someone who lived in New Orleans and, say, evacuated their home and incurred damage to their property or other valued possessions. Vague, all-encompassing survey measures of experience cannot capture the nuances of or distinguish among these different experiences.

The other common approach is to measure experience with two or more questions that aim to capture different 
aspects of experience, which are then combined into one variable (e.g., Lindell and Hwang 2008; Trumbo et al. 2011). The aspects that are typically asked about are people's experiences with evacuating from a hurricane, property damage, and injury. Often, these experiences are measured both as they pertain to survey respondents but also to their family or friends as a way to capture vicarious experiences. Although this approach begins to better capture the complexity of people's hurricane experiences, combining different experiences into one variable removes the ability to understand their potentially different effects.

Most experience measures that researchers utilize capture tangible aspects of people's hurricane experiences, that is, those that pertain to physical or bodily exposure and consequent impacts. The measures discussed above regarding experience with multiple hurricanes, evacuation, and property damage are example measures of tangible experiences. Some scholars have noted the importance of also capturing intangible experiences-that is, people's interpretations of their experiences and the meaning they attach to them (Barnett and Breakwell 2001; Zaalberg et al. 2009). Such measures may capture an amalgam of people's experiences from one or multiple events, as well as the ways that the effects of experiences can endure and change over time. Only a few studies, however, have employed quantitative measures of people's intangible hurricane experiences (Barnett and Breakwell 2001; Lazo et al. 2015).

Here, we build on the work that has been done to date by measuring and separately analyzing six different past hurricane experiences, including both tangible and intangible experiences [see section $3 b(1)$ ].

\section{b. Influence of past hurricane experience on evacuation, empirically and theoretically}

The influence of past hurricane experience on evacuation behaviors (actual and intended) has been examined in dozens of studies. The empirical findings are mixed, however, suggesting that past experience can have a positive, negative, or no influence on evacuation decisions [see Baker (1991), Lindell (2012), Huang et al. (2016), and Lazo et al. (2015) for reviews]. In fact, in a statistical meta-analysis of hurricane studies published since 1991, Huang et al. (2016) report that two-thirds found a nonsignificant relationship between experience and evacuation.

One plausible reason for these results may be the way experience tends to be measured, such as with the aforementioned vague, all-encompassing items or with indiscriminate composites of items. Although our goal here was not to fully explicate past experience, we did aim to better capture nuances of this concept with our six measures, which we separately analyzed in conjunction with evacuation behaviors.

Another plausible reason for the mixed empirical findings is that past hurricane experience may exert its influence on evacuation behaviors through intervening mechanisms. In other words, the effect of past experience may be mediated, as theorized by behavioral response models such as protection motivation theory (PMT; Rogers 1975, 1983) and the Protective Action Decision Model (PADM; Lindell and Perry 2012). Although the terminology differs by model, both theorize that when people become aware of a risk, they draw on information, including their past experiences, which initiates appraisals of risk perception and efficacy beliefs. Risk perception ${ }^{1}$ was theorized as a solely cognitive process in PMT (and in many other theories of protective behavior that were developed in the 1970s and 1980s; see, e.g., Weinstein 1993), meaning individuals systematically evaluate their chance of being affected by a hazard and how harmful it will be. Since then, the affective dimension of risk perception, which is the underlying good or bad feeling one has about a hazard, has been become widely understood as being very important. The affective mode of risk perception is intuitive and emotional and therefore faster, and it works in tandem with the slower, effortful, cognitive mode of risk perception (Slovic et al. 2004; Slovic 2010; Greenberg et al. 2012). The role of affective risk perception is noted in the PADM. Efficacy ${ }^{2}$ also consists of multiple dimensions, including individuals' self efficacy, or beliefs about their ability to perform the recommended behavior, and response efficacy, or beliefs about the effectiveness of the recommended response in reducing risk.

To summarize, these models theorize that individuals' past hazard experiences (among other antecedent variables) affect their cognitive judgments and emotional reactions about the possibility of harm due to a hazard (i.e., risk perception) as well as their beliefs about responding to that hazard (i.e., efficacy beliefs). These in turn affect responses, such as evacuation, to a risk (Fig. 1).

Although these mediated relationships have been theorized, very little work has been done to empirically examine them in the context of hurricanes. Most hurricane studies that have investigated these concepts have examined only parts of this model, with a focus on

\footnotetext{
${ }^{1}$ Termed "threat appraisal" in PMT and "threat perception" in PADM.

${ }^{2}$ Termed "coping appraisal" in PMT and "protective action (or hazard adjustment) perceptions" in PADM. Some of aspects of the PADM protective action perceptions are broader than self and response efficacy; for details, see Lindell and Perry (2012).
} 


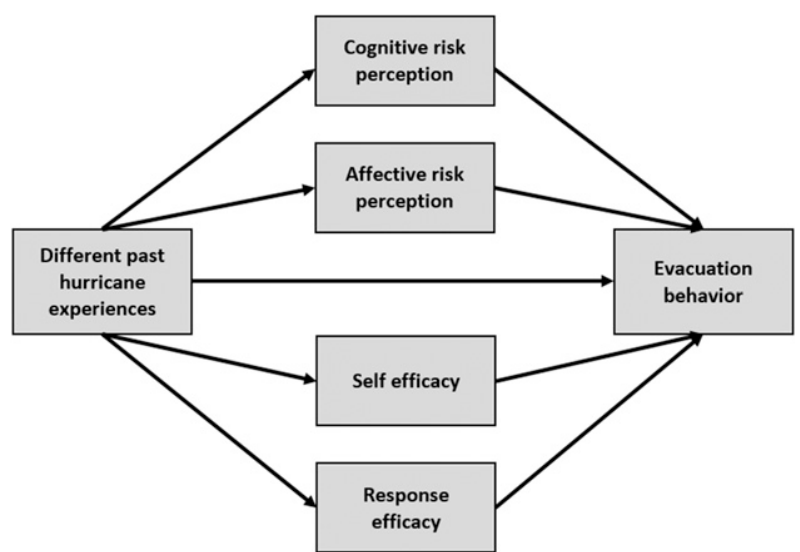

FIG. 1. Theoretical model illustrating how different past hurricane experiences can exert an influence on future evacuation behavior through the intervening dimensions of cognitive and affective risk perception and of self efficacy and response efficacy.

whether relationships exist between risk perception and evacuation behaviors (Peacock et al. 2005; Burnside et al. 2007; Huang et al. 2012; Lindell 2012; Lazo et al. 2015), past experience and risk perception (Peacock et al. 2005; Matyas et al. 2011; Trumbo et al. 2011), and past experience and evacuation behaviors (Baker 1991; Huang et al. 2016; Lazo et al. 2015; Morss et al. 2016a). Only a few mediation studies have been conducted that examine how hurricane experience is mediated by either risk perception or efficacy to affect future protective behaviors. Huang et al. (2012) showed that past hurricane experience increased perceived likelihood of different expected personal impacts of a real future hurricane threat, which enhanced evacuation decisions. Meyer et al. (2013) developed an experimental context with a hypothetical hurricane and found that past hurricane experience decreased negative affect, which decreased evacuation intention. And Norris et al. (1999) found that past hurricane experience increased efficacy beliefs (including both response- and self-efficacy measures, termed "perceptions of control"), which increased general protective behaviors for a future hazard.

Here, we add to the extant research by drawing on risk theories of behavior to investigate how people's past hurricane experience is mediated by multiple dimensions of risk perception (cognitive, affective) and efficacy (selfefficacy, response efficacy) to influence evacuation intention (Fig. 1). Moreover, we examine different past hurricane experiences as antecedents in this multiple mediator model to explore the different effects they might have. We explore these presumed causal processes guided by the aforementioned risk theories as well as by the nature of our research of interest, which is to investigate how people's past experiences affect their future judgments and decisions. These analyses are based on a survey of at-risk coastal residents in MiamiDade County, Florida, who were provided with a hypothetical hurricane scenario. Details of the research methods are provided next.

\section{Methods}

\section{a. Survey sampling and implementation}

A brief description of the survey sampling and implementation are provided here; full details are available in Morss et al. (2016a).

The survey included a hypothetical scenario of a hurricane threatening landfall near Miami, Florida, further discussed below. Based on this scenario and our interest in studying factors influencing hurricane evacuation decision-making, our target population was Miami-Dade County residents along coastal areas. Specifically, we targeted the two highest-risk evacuation zones (A and B) to reach people for whom evacuation would be the recommended behavioral response.

Survey sampling and data collection were managed by the survey research company Knowledge Networks (KN, now GfK). KN randomly sampled residences from all Miami-Dade County census blocks containing some portion of evacuation zone A and/or B. KN recruited respondents by postal mail, sending invitation letters to 17050 addresses, and participants responded to the survey on the web using their existing Internet access. The survey was implemented from November 2011 to January 2012, and it was fielded in both English and Spanish. KN received 260 completed surveys. Four respondents completed the survey in less than $10 \mathrm{~min}$ (the median survey completion time was $33 \mathrm{~min}$ ), and one respondent skipped nearly half of the survey questions. These five people were removed, leaving an analysis dataset with 255 respondents.

Demographically, a majority of respondents were male $(56.0 \%)$, most were employed $(72.4 \%)$, and they had a median age of 46 , education of 16 years, and a household size of two people. The median number of years residing in Miami-Dade County was 12 years, and a majority of respondents own their residence $(61.2 \%)$ and reside in a building with two or more apartments (63.5\%). Most respondents are white (83.5\%), and 38.5\% are of Spanish, Hispanic, or Latino descent. Finally, about one-third of respondents reside in evacuation zone A and one-half are in zone B; the remainder resides just outside of these zones, because of the census block-based sampling approach (Morss et al. 2016a, their Fig. 3).

Again, the goal of our study is to investigate the mediated relationships suggested by theories of behavioral 
responses to risks; thus, we focus on studying these processes (Frick 1998, Hayes 2005).

\section{b. Survey design and measurement}

The survey instrument was developed collaboratively by research team members, informed by related prior research. Input also was solicited from meteorological researchers as well as weather and emergency response practitioners whose work pertains to hurricanes. A brief summary of the survey structure is provided here, followed by a detailed description of the concepts and measures that are the focus of this article.

The survey began with questions about respondents' past hurricane experiences, which are discussed further below [section $3 \mathrm{~b}(1)$ ]. After additional questions about hurricanes in general, respondents were presented with a scenario of a hypothetical hurricane named Julia that was threatening Miami-Dade County (Morss et al. 2016a, their Figs. 1 and 2). All respondents were informed that Julia was a Category 4 hurricane that might affect Miami within $48 \mathrm{~h}$. Respondents were then randomly assigned some combination of five risk messages. Every respondent received a graphic emulating the National Hurricane Center's cone of uncertainty, either with or without the track line. Respondents also were assigned to receive or not receive up to four textual risk messages that included Julia-related information about the probability of landfall in Miami, storm surge depth and extent, storm surge impacts, and evacuation for protection. Several of these messages had an effect on respondents' evacuation intention and other responsesthe details of which are the focus of the paper by Morss et al. (2016a) - thus, we control for these messages in the analyses presented here.

After reviewing the risk messages provided to them, respondents were asked questions about their evacuation intention, risk perceptions, and efficacy beliefs as they pertained to the Hurricane Julia scenario. The survey items used to measure these concepts are discussed in detail below [sections $3 \mathrm{~b}(2)$ and $3 \mathrm{~b}(3)$ ] and in the appendix.

At the end of the survey, respondents were asked about their individual and household characteristics, including their age, gender, education, employment, race, ethnicity, primary language, length of residence in Miami-Dade County, residence ownership, residence type, and household size. Data were also collected to measure cultural worldviews, that is, people's beliefs about social structures and networks, which have been shown to influence risk perceptions and responses (Tansey and O'Riordan 1999; McNeeley and Lazrus 2014). The relationships between each of the demographic and cultural worldview variables and participants' responses to the Hurricane Julia scenario are discussed in Morss et al. (2016a). All of these variables were included here as statistical controls in the mediation analyses. For these questions, data were missing from $0 \%$ to $8.6 \%$ of respondents, and thus they were imputed with median values.

\section{1) Measures of the ANTECEDENT VARIABLES: PAST HURRICANE EXPERIENCES}

Survey respondents were asked about six different aspects of experience with any or all past hurricane events (rather than with a specific hurricane). One item measured whether or not the respondent had experience with a tangible protective action taken in response to a hurricane threat, specifically as experience with evacuating because of a hurricane threat. Three items measured whether or not the respondent had ever had any experiences with tangible impacts due to a hurricane, including damage or property loss, other financial losses, and injury or death. The final two items measured two intangible impacts. One item measured whether or not the respondent had ever experienced emotional impacts or personal distress (hereafter referred to simply as emotional impacts) because of a hurricane. The other item measured how severe the impacts of the respondent's own hurricane experiences have been overall. This item mirrors a concept termed "threat experience appraisal" that was developed by Grothmann and Reusswig (2006) to measure one's perceived severity of a (flood) threat experienced in the past. The complete wording of the experience questions and response options is provided in Table 1. Note that, excepting the final item that measures overall severity of hurricane impacts, the other questions asked about experiences of the respondent or anyone in their household.

Data were missing from between one and three respondents for three of the experience measures and were imputed with the median value. ${ }^{3}$ No data were missing for the other three experience measures.

\section{2) MEASURES OF MEDIATING VARIABLES: RisK PERCEPTION AND EFFICACY BELIEFS}

Respondents were asked survey questions to measure the dimensions of risk perception and of efficacy beliefs discussed above (section 2b, Fig. 1) as they pertained to the threat of the hypothetical Hurricane Julia.

\footnotetext{
${ }^{3}$ Median imputation is considered adequate when less than 5\% of data are missing for a variable (Harrell 2001); otherwise, alternative data imputation techniques are recommended for key variables of interest (Baraldi and Enders 2010).
} 
TABLE 1. Distribution of respondents' past hurricane experiences $(n=255)$.

\begin{tabular}{|c|c|c|c|c|c|c|c|}
\hline \multirow[b]{2}{*}{ Experience measure } & \multicolumn{7}{|c|}{ Response options and distributions } \\
\hline & $\mathrm{No}=0^{\mathrm{a}}$ & Yes $=1$ & & & & & \\
\hline \multicolumn{8}{|l|}{ Have you or has anyone in your household ever... } \\
\hline $\begin{array}{l}\text {...evacuated or left your residence to go some- } \\
\text { place safer in response to the threat of a hurricane? }\end{array}$ & $54.1 \%$ & $45.9 \%$ & & & & & \\
\hline $\begin{array}{l}\text {...had damage to or loss of property because of } \\
\text { a hurricane? }\end{array}$ & $43.9 \%$ & $56.1 \%$ & & & & & \\
\hline ...had any other financial losses such as business & $73.3 \%$ & $26.7 \%$ & & & & & \\
\hline $\begin{array}{l}\text { losses or loss of income because of a hurricane? } \\
\text {. .been injured (including loss of life) due to } \\
\text { a hurricane? }\end{array}$ & $98.0 \%$ & $2.0 \%$ & & & & & \\
\hline \multirow{2}{*}{$\begin{array}{l}\text {...had emotional impacts or personal distress be- } \\
\text { cause of a hurricane? }\end{array}$} & $56.1 \%$ & $43.9 \%$ & & & & & \\
\hline & $\begin{array}{l}\text { Not at all } \\
\quad \text { severe }=1^{\mathrm{b}}\end{array}$ & 2 & 3 & $\begin{array}{l}\text { Moderately } \\
\quad \text { severe }=4\end{array}$ & 5 & 6 & $\begin{array}{l}\text { Extremely } \\
\quad \text { severe }=7\end{array}$ \\
\hline $\begin{array}{l}\text { Overall, how severe have the impacts of your own } \\
\text { hurricane experience(s) been? }\end{array}$ & $21.6 \%$ & $9.4 \%$ & $16.5 \%$ & $28.2 \%$ & $12.5 \%$ & $7.5 \%$ & $4.3 \%$ \\
\hline
\end{tabular}

Cognitive risk perception was measured with six items (e.g., "It is likely that Hurricane Julia will hit my residence", "I believe that the damages from Hurricane Julia will be devastating"), each on a seven-point scale from "very strongly disagree" to "very strongly agree." Affective risk perception was measured by asking respondents to indicate how they feel about Hurricane Julia and then providing a series of emotion-related adjectives using a seven-point semantic differential, which is a response scale that has opposite adjectives on either end (e.g., assured to worried). Four items were used where higher values represent negative affect (i.e., worried, fearful, anxious, dread) and lower values represent positive affect (i.e., assured, fearless, at ease, confident). The 10 risk perception items factor analyzed cleanly into cognitive and affective dimensions (see the appendix for the factor analysis results and for the wording, mean, and standard deviation of each survey item). The six cognitive and four affective risk perception items were summed into separate scales where higher values represent greater cognitive (Cronbach's $\alpha=0.87)^{4}$ and negative affective (Cronbach's $\alpha=0.86$ ) risk perception, respectively.

Self efficacy was measured with three items (e.g., "I would be able to do what is needed in order to

\footnotetext{
${ }^{4}$ Cronbach's $\alpha$ is a statistical coefficient that estimates the reliability of a set of measurement items as the proportion of total variance among a set of items that is communal. The coefficient ranges from 0 to 1 , with higher values representing greater reliability.
}

evacuate"), each on a seven-point scale from "very strongly disagree" to "very strongly agree." Response efficacy also was measured with three items (e.g., "Evacuation would be effective to prevent injury or death"), each on the same seven-point scale. The six efficacy items factor analyzed cleanly into the self and response dimensions (see the appendix for the factor analysis results and for the wording, mean, and standard deviation of each survey item). The three items for each dimension were summed into a scale where higher values represent greater self efficacy (Cronbach's $\alpha=0.89$ ) and response efficacy (Cronbach's $\alpha=0.90$ ), respectively.

Data were missing from between zero and three respondents across all of the risk perception and efficacy survey measures, so they were imputed with median values.

\section{3) Measure of the DePendent VARiable: HURRICANE EVACUATION INTENTION}

The dependent variable of interest, hurricane evacuation intention, was measured with a single survey item. Immediately after respondents were shown the hypothetical hurricane scenario and risk messages, they were asked, based on the information they had received about Hurricane Julia, to indicate how likely it is that they would evacuate on a scale of 0 to 10 , where 0 means "I definitely would NOT evacuate" and 10 means "I definitely WOULD evacuate." No data were missing for this question. The distribution of evacuation intention is 


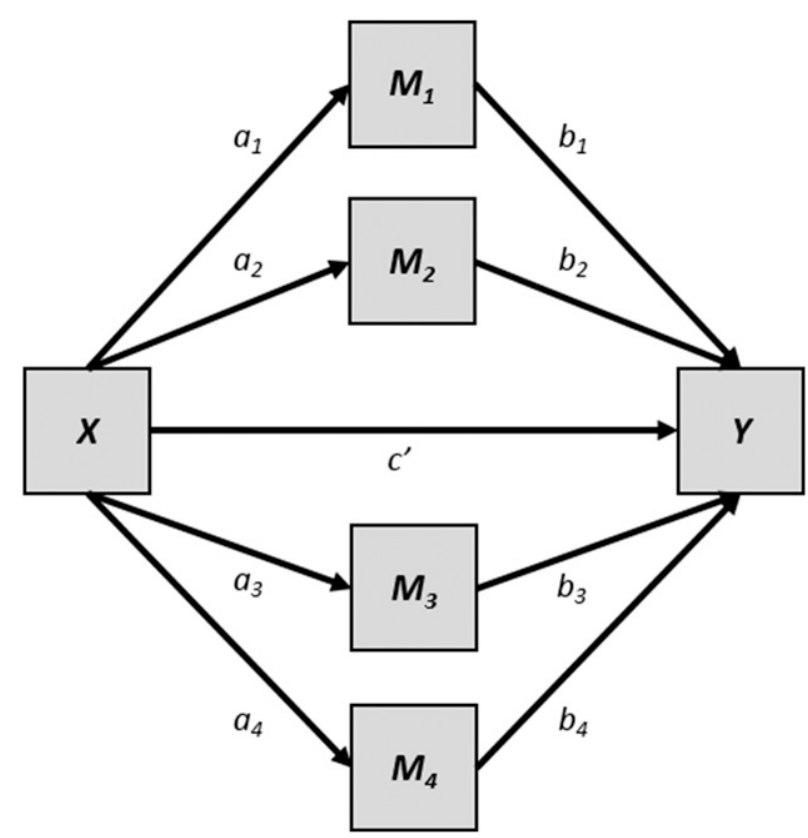

FIG. 2. Conceptual representation of a parallel mediation model with four mediators, showing the influence of $X$ on $Y$ directly (path $c^{\prime}$ ) and indirectly via $M_{1}$ (through paths $a_{1}$ and $b_{1}$ ), $M_{2}$ (through paths $a_{2}$ and $b_{2}$ ), and so on.

skewed to the left $($ mean $=7.0$, standard deviation $=$ 2.9 ), with the most common response, from $28.4 \%$ of respondents, being that they definitely would evacuate.

\section{c. Parallel mediation analysis}

This section briefly describes mediation analysis conceptually and statistically. Complete details of this method and the analytical steps followed here are available in Hayes (2013).

Mediation analysis is used to investigate how an antecedent variable $(X)$ exerts its influence on an outcome variable $(Y)$ through one or more intervening variables, termed mediators $(M)$. As discussed above, we utilize mediation analysis here to explore how each of the different measures of past hurricane experience $(X)$ influences evacuation intention $(Y)$ through four mediators $\left(M_{j}\right)$ - that is, the two risk perception and two efficacy dimensions-operating in parallel.

A conceptual representation of a parallel mediation model with four mediators is shown in Fig. 2. The model illustrates that there are five paths by which $X$ influences $Y$ : directly through path $c^{\prime}$ and indirectly via $M_{j}$ through paths $a_{j}$ and $b_{j}$. Statistically, these paths are represented with linear regression through two equations ${ }^{5}$ :

\footnotetext{
${ }^{5}$ Across the linear regression equations, $i$ represents the intercept; $a_{j}, b_{j}$, and $c^{\prime}$ represent partial regression coefficients; and $\varepsilon$ represents the error term.
}

$$
M_{j}=i_{M_{j}}+a_{j} X+\varepsilon_{M_{j}} \text { for all } j=1 \text { to } 4
$$

and

$$
Y=i_{Y}+c^{\prime} X+\sum_{j=1}^{j=4} b_{j} M_{j}+\varepsilon_{Y}
$$

Expanding Eq. (2) yields

$Y=i_{Y}+c^{\prime} X+b_{1} M_{1}+b_{2} M_{2}+b_{3} M_{3}+b_{4} M_{4}+\varepsilon_{Y}$.

These equations determine how each of the paths represented in Fig. 2 are statistically estimated. Equation (3) reveals a benefit to conducting a parallel mediation analysis: a mediated relationship via a given mediator $M_{j}$ is examined while controlling for the other mediators with which $M_{j}$ may be correlated. This helps reduce the possibility that a proposed mediator may be related to $Y$ because it is correlated with a different mediator that is the causal influence.

Further, substituting Eq. (1) into Eq. (3) and collecting terms ${ }^{6}$ yields the following model, which illustrates how the direct and indirect effects are calculated ${ }^{7}$ :

$Y=i_{Y}^{*}+\left(c^{\prime}+a_{1} b_{1}+a_{2} b_{2}+a_{3} b_{3}+a_{4} b_{4}\right) X+\varepsilon_{Y}^{*}$.

The direct effect of $X$ on $Y$ is $c^{\prime}$. An indirect effect is the product of the $a_{j}$ and $b_{j}$ path linking $X$ to $Y$ through a given mediator $M_{j}$. There are as many indirect effects as there are mediators; thus, in all analyses presented here, there are four indirect effects. Each respective indirect effect is termed a specific indirect effect, and their sum is the total indirect effect.

The sum of the direct and indirect effects is termed the total effect $c$ :

$$
c=c^{\prime}+\sum\left(a_{j} b_{j}\right), \text { for } j=1 \text { to } 4 .
$$

The total effect $c$ is the coefficient that would be statistically estimated if $Y$ were regressed onto $X$ alone, in the absence of any mediators. Equation (5) indicates how direct and indirect effects may exist but offset, resulting in an insignificant total effect. This phenomenon occurs in the analysis presented here, as will be shown and discussed later.

\footnotetext{
${ }^{6} i_{Y}^{*}=i_{Y}+\Sigma b_{\mathrm{j}}^{*} i_{M j}$ and $\mathcal{E}_{Y}^{*}=\mathcal{E}_{Y}+\Sigma b_{j}^{*} \mathcal{E}_{M j}$.

${ }^{7}$ As discussed in Hayes (2009) and chapter 6 in Hayes (2013), it is important to report the value of the indirect effect rather than (as is often done) claiming partial or complete mediation based on the statistical significance of the $a$ and $b$ path coefficients in conjunction with the magnitudes of the direct $\left(c^{\prime}\right)$ and total $(c)$ effects.
} 
The above equations can be generalized to include additional variables as statistical controls. As noted above, the five risk messages about Hurricane Julia and the demographic characteristics and cultural worldviews were included as covariates in the analyses.

All analyses were performed in the Statistical Package for the Social Sciences (SPSS), version 22, using Hayes's freely available PROCESS macro, version 2.12.1 (Hayes 2016). The direct, specific indirect, and total effects are reported for each mediation analysis. Inferences for the point estimate of the direct and total effects come directly from the linear regression analyses through null hypothesis significance testing (i.e., based on the $p$ value of the test statistic for the coefficients $c^{\prime}$ or $c$ ). However, this method of statistical inference cannot be used for the indirect effect, which is a product $\left(a_{j} b_{j}\right)$ of two regression coefficients and thus has a nonnormal sampling distribution, which violates an important assumption for statistical inference using null hypothesis significant testing. Instead, sampling distributions of the specific indirect effects were empirically derived from 10000 bootstrapped estimates calculated using the bias-corrected method (Preacher and Hayes 2008; Hayes 2013). The 90\% and 95\% confidence intervals based on the bootstrapped sampling distributions, all generated using the same seeded value, are reported. Because confidence intervals are reported for the indirect effects, we also report them for the direct and total effects, along with the $p$ values of the point estimates.

\section{Results: Past hurricane experiences}

This section describes the prevalence of the six different aspects of past hurricane experience that were measured for this sample, as well as the relationships among the experiences.

The distribution of responses for each of the six experience measures is shown in Table 1 . As previously noted, all questions measured experiences of the respondent or their household members, except for the measure of severity of overall impacts, which pertained to the respondent only.

Looking first at the measures of tangible experiences, nearly half of respondents have experience with evacuating to someplace safer in response to the threat of a hurricane, and more than half have experienced damage or some other type of property loss. Other financial losses are less common, experienced by about one-quarter of respondents. Only five respondents indicated that they or a household member have been injured or that a household member has died because of a hurricane. Because so few respondents had this experience, the statistical power of this variable is limited and thus it was omitted from further analyses. However, all five people who reported injury or death experience also reported they had experience with property damage and with emotional impacts. Of the two measures of intangible experiences, nearly half of respondents have experienced emotional impacts due to a hurricane, and more than half report that the impacts of their overall hurricane experiences are of moderate to extreme severity.

Correlations between all pairs of the experience variables show that each type of experience is significantly and strongly correlated with all other types, excepting the omitted injury item, suggesting that many of these aspects of experience are interwoven (Table 2). In particular, the two intangible experiences-emotional impact and overall severity of impacts-each are highly correlated with each of the tangible experiences.

We further explored these relationships by combining whether people have experiences with evacuation, property damage, and other financial losses into a summed scale that represents the number of these tangible experiences that respondents have. Then, we examined this in conjunction with each of the intangible experience measures. As shown in Fig. 3, there is a monotonic increase in the percentage of people who report that they have experienced emotional impact with each additional tangible experience had $\left[\chi^{2}(3, n=255)=62.8, p<0.01\right]$. Figure 4 presents a similar analysis and shows that respondents report increasing severity of impacts with more tangible experiences $(r=0.54, p<0.01)$.

Importantly, Figs. 3 and 4 also show that some respondents who do not have any experience with evacuating, property damage, or financial loss still report emotional impact $(13 \%)$ and moderate to extreme severity of impacts $(17 \%)$. This suggests that people can be significantly affected by hurricanes even if they have not experienced any of the major tangible aspects of a hurricane that threatens or makes landfall in their region.

\section{Results: Mediation analyses}

This section reports the results of the parallel mediation analyses. Five analyses are reported, one with each different hurricane experience (i.e., experience with past evacuation, property damage, financial loss, emotional impact, overall severity of impacts) as the antecedent variable. All of the mediation analysis results are reported in Table 3, including the direct effect, four specific indirect effects (i.e., for each mediator), and total effect. Given our goal of exploring the theorized mediated processes by which past experience can influence future behavioral response, which can be built on in future work, we discuss results that are significant at the $90 \%$ level (i.e., the $90 \%$ confidence interval does not contain zero), most of which also are significant at the 


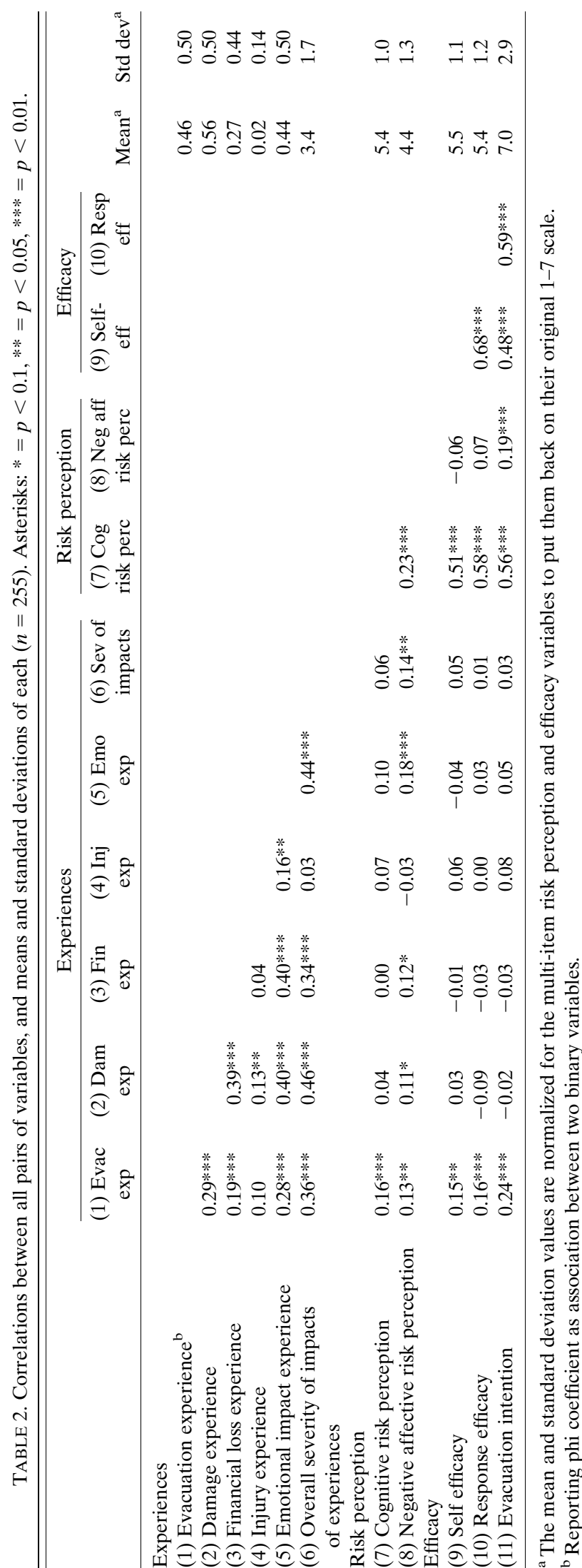

95\% level. The unstandardized effects are reported for all results so that they can be directly interpreted vis-àvis the measurement scales used (Kim and Mueller 1981; Preacher and Kelly 2011). As a complement to the table, we also include figures that visually depict the results for evacuation experience (Fig. 5) and for emotional impacts (Fig. 6).

The complete set of regression results for the mediation analyses is available in an online supplement. For each of the five different antecedent experiences examined, there are five regressions-one for each of the four mediators as the dependent variable [section $3 \mathrm{c}$, Eq. (1)] and one with evacuation intention as the dependent variable [section 3c, Eq. (2)] - for a total of 25 regressions (Tables $\mathrm{S} 1-\mathrm{S} 25$ in the online supplement). As discussed above, all regressions control for the five risk messages about Hurricane Julia and the demographic characteristics and cultural worldviews (section $3 b$ ), and the evacuation intention regression further controls for the four mediators (section 3c). The focus of this article is on the mediated relationships between experience and evacuation intention, rather than on the mediating variables themselves or the control variables. However, to provide context for the mediation results, and for readers interested in these mediating or control variables, we briefly note a few results here.

First, all four mediators-cognitive and negative affective risk perception, and self and response efficacyare strongly and consistently associated with increased evacuation intentions (see also the $b$ paths in Figs. 5 and 6 and Table 3). Moreover, increased evacuation intentions are associated with respondents who are older, female, Spanish-speaking, and of Hispanic ethnicity (cf. Baker 1991; Huang et al. 2016; Lazo et al. 2015; Morss et al. 2016a). As mentioned above (section 3b), several of the experimental risk messages also affected evacuation intentions, which is why we controlled for them. Finally, the different risk perception and efficacy dimensions are influenced by different respondent characteristics, but some-including age, length of residence, and individualist worldview-influence most or all of these mediators [for risk perception, compare Peacock et al. (2005) and Trumbo et al. (2016)]. Morss et al. (2016a) further discuss the influence of the respondent characteristics and the risk messages on evacuation intentions, and the influence of individualist (and egalitarian) worldviews on risk judgments and responses is investigated further in follow-on work (R. E. Morss et al. 2016, unpublished manuscript).

\section{a. Tangible protective action: Past evacuation experience}

The mediation analysis with past evacuation experience indicates that it had a significant, positive influence 


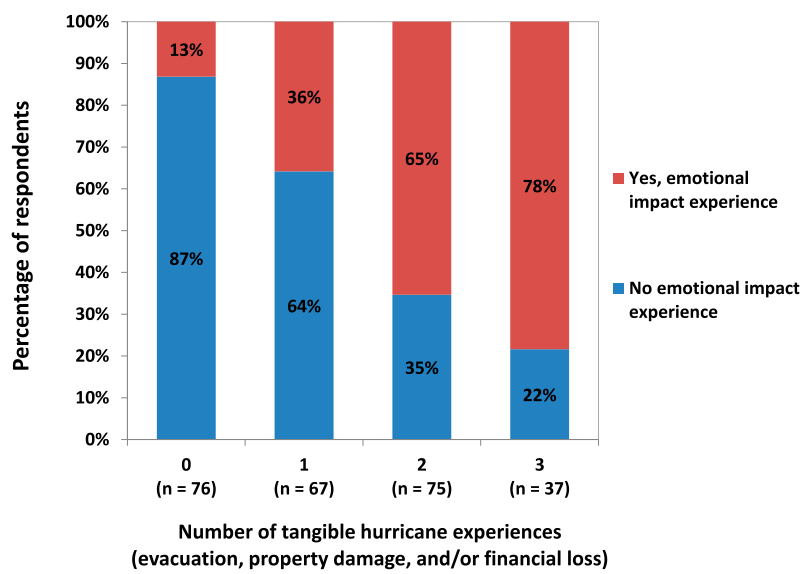

FIG. 3. Variation in emotional impact or personal distress experience with the number of evacuation, damage, and/or financial loss experiences $(n=255)$.

on evacuation intention indirectly through all four mediating variables (Table 3, Fig. 5). In other words, respondents' past experiences evacuating from a hurricane increased their risk perceptions, that is, their perceptions that they would be affected and harmed by Hurricane Julia (cognitive), and their Julia-related feelings of fear, worry, dread, and anxiety (negative affective). In turn, these risk perceptions increased their reported likelihood of evacuating because of Julia. Respondents' past evacuation experience also increased their efficacy beliefs, that is, regarding their ability to evacuate from Julia (self efficacy) and the effectiveness of evacuating to reduce harm (response efficacy), and these also increased evacuation intentions.

The results also show that there is a significant, positive total effect $(c=1.59)$ of respondents' past evacuation experience on their reported intention to evacuate from Hurricane Julia. Proportionally, the sum of all four indirect effects $\left(\Sigma a_{j} b_{j}=0.64\right.$; Fig. 5) represents about $40 \%$ of the total effect in this analysis (Preacher and Kelly 2011; Hayes 2013). The other $60 \%$ is attributed to the direct effect of past evacuation experience. This suggests that past evacuation experience influences likelihood of future evacuation in ways other than through the intervening variables we explored here; this is discussed further in section 6 .

\section{b. Tangible impacts: Property damage experience and financial loss experience}

The mediation analysis with property damage experience revealed only one significant indirect effect. Respondents' past experience with property damage due to a hurricane decreased response-efficacy perceptions, causing a negative indirect effect on

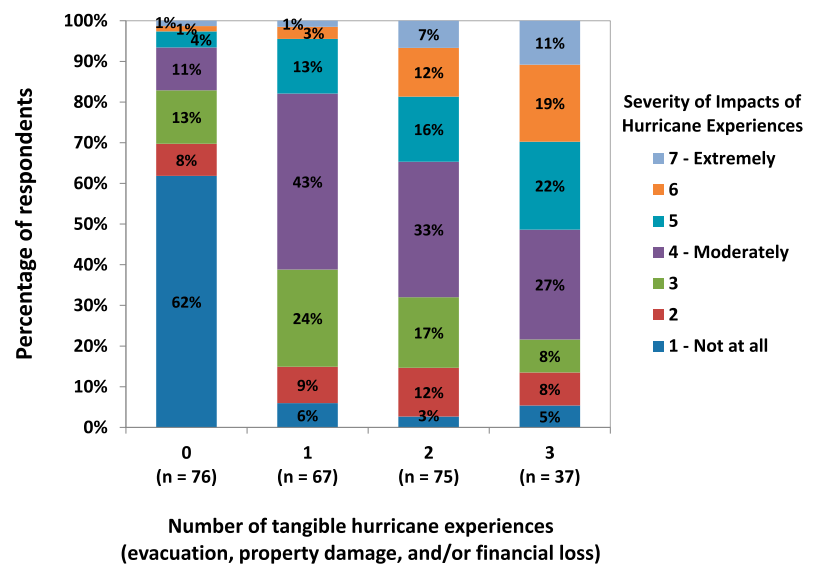

FIG. 4. Variation in severity of impacts with the number of evacuation, damage, and/or financial loss experiences $(n=255)$.

evacuation intentions (Table 3). This means that people who have suffered property damage from a hurricane are less likely to think that evacuating is an effective way to reduce harm, and thus they report that they are less likely to leave for Hurricane Julia. There was no other evidence of mediated, total, or direct effects of property damage experience on evacuation intentions.

The mediation analysis with hurricane-related financial loss (e.g., business losses or loss of income) experience also revealed only one significant indirect effect. Respondents with this experience had increased feelings of fear, worry, dread, and anxiety (negative affect) about Hurricane Julia, which in turn resulted in higher evacuation intentions (Table $3)$. There were no other effects of financial loss experience.

\section{c. Intangible impacts: Emotional impact experience and overall severity of impacts experienced}

Experience with emotional impacts due to a past hurricane significantly influenced evacuation intention through two mediators, but, importantly, these two mechanisms operate in opposite ways (Table 3, Fig. 6). Respondents' past emotional experience increased their fear, worry, dread, and anxiety (negative affect) about Hurricane Julia, which in turn increased their evacuation intentions, resulting in a positive indirect effect $\left(a_{2} b_{2}=0.10\right)$. However, respondents' past emotional experience also decreased their belief in their ability to evacuate from Hurricane Julia to reduce their hurricane risk (self efficacy), resulting in a negative indirect effect $\left(a_{3} b_{3}=-0.10\right)$. Thus, past emotional experience heightened negative affect, which helped motivate protective behavioral response, but this effect was dampened by lower self 


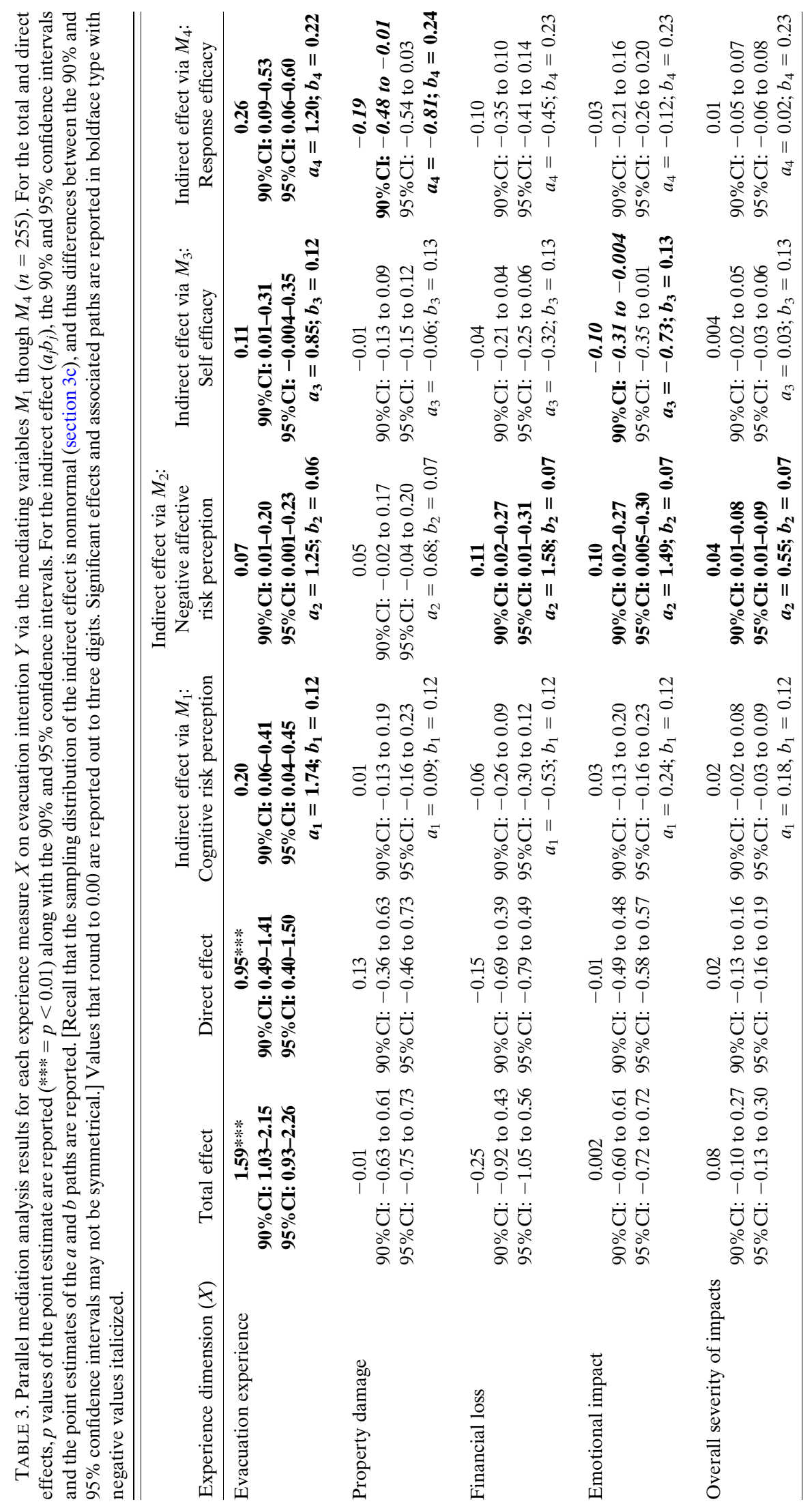




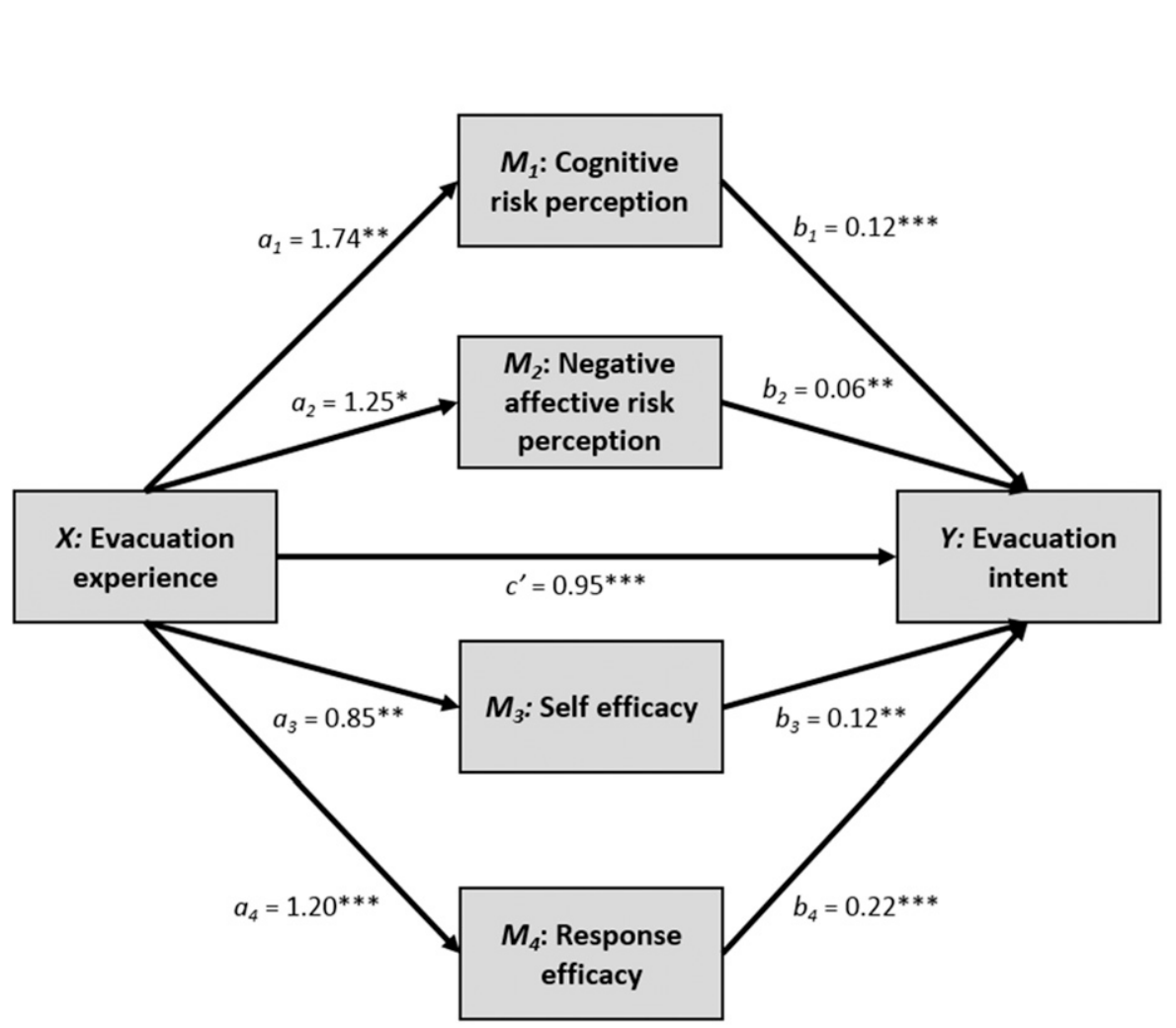

Indirect effects: point estimate and confidence intervals

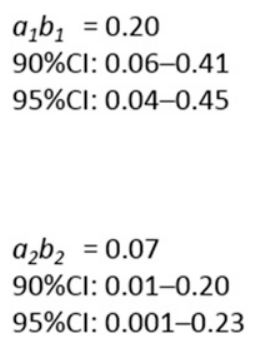

Total indirect effect $=0.64$

90\% Cl: $0.29-1.02$

95\% $\mathrm{Cl}: \quad 0.22-1.11$

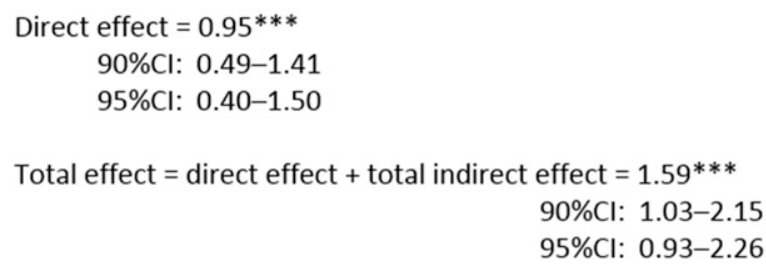

FIG. 5. Parallel mediation model showing the direct $\left(c^{\prime}\right)$ and indirect $\left(a_{j} b_{j}\right)$ paths by which past evacuation experience influences evacuation intent $(n=255)$. Indirect, direct, and total effects are reported, along with their respective $90 \%$ and $95 \%$ confidence intervals. Statistical control variables are not represented in the model for simplicity.

efficacy to perform the protective action. In other words, these indirect effects of past emotional experience compete, and this contributes to why there is no significant total effect of past emotional experience on evacuation intention. No other significant mediated relationships emerged.

Last, the mediation analysis indicates that the severity of impacts of respondents' hurricane experiences indirectly increased evacuation intentions through negative affective risk perception (Table 3). Thus, the more severe the impacts from respondents' past experiences, the more likely they were to feel fear, worry, dread, and anxiety; in turn, these perceptions increased intentions to evacuate for Julia. This indirect effect was weak, however, and there were no other effects of severity of impacts experienced (Table 3).

\section{Summary and discussion}

The broad notion of one's past "experience" with a hazard can encompass many different aspects, which can influence how one judges and responds to a future risk situation. Based on a survey of Miami-Dade County, Florida, coastal residents who are at risk from 
Indirect effects: point estimate and confidence intervals

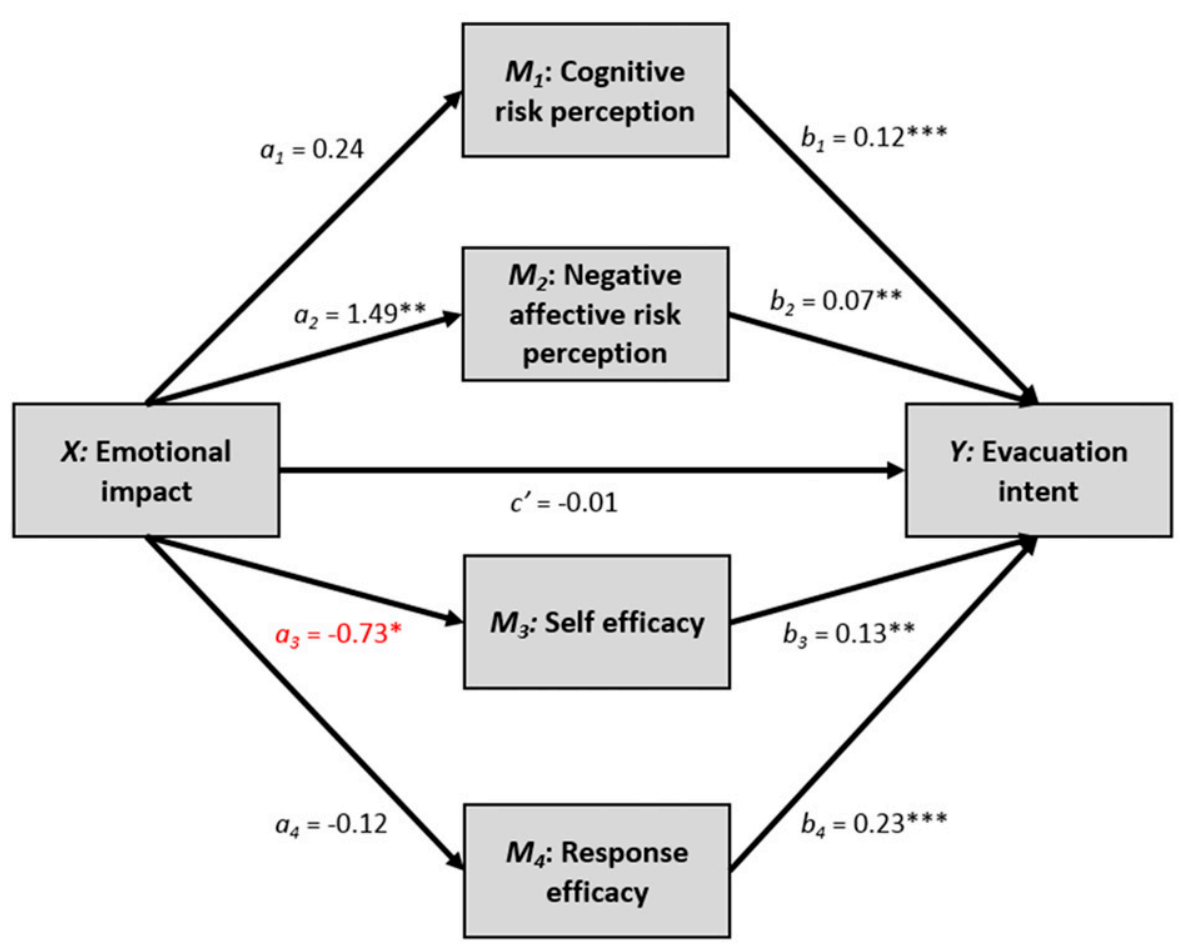

$a_{1} b_{1}=0.03$

90\%Cl: $-0.13-0.20$

95\%Cl: $-0.16-0.23$

$a_{2} b_{2}=0.10$

90\% Cl: $0.02-0.27$

95\%Cl: $0.005-0.30$

$a_{3} b_{3}=-0.10$

90\%Cl: $-0.31--0.004$

95\%Cl: $-0.35-0.01$

Total indirect effect $=0.01$

$90 \% \mathrm{Cl}:-0.40-0.38$

95\% Cl: $-0.48-0.45$

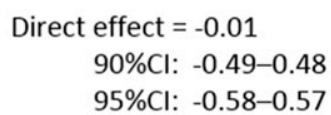

Total effect $=$ direct effect + total indirect effect $=0.002$

$90 \% \mathrm{Cl}:-0.60-0.61$

95\% Cl: $-0.72-0.72$

$* \mathrm{p}<0.1, * * \mathrm{p}<0.05, * * * \mathrm{p}<0.01$

FIG. 6. As in Fig. 5, but with emotional impact experience. Negative paths and negative effects are shown in red text.

hurricanes, this study explored dimensions of past hurricane experiences and their effects on evacuation intentions in two ways. First, we measured and examined six different aspects of hurricane experiences-a tangible protective behavioral response (evacuation), three tangible impacts (property damage, financial loss, injury or death), and two intangible impacts that represent people's interpretations of their experiences (emotional impact or personal distress, overall severity of impacts from all hurricane experiences)-and relationships among them. Second, we drew on theories of behavioral responses to risks and investigated how these respective past hurricane experiences influenced evacuation intent in a hypothetical hurricane scenario as mediated by dimensions of risk perception (cognitive, negative affect) and efficacy beliefs (self efficacy, response efficacy).

Our investigation of different aspects of experience provides insight into the multifaceted nature of people's past experiences. In particular, the results reveal the importance of better understanding intangible impacts from hurricane experiences, which tend to be less commonly investigated by researchers. Respondents were more likely to report experiencing hurricane-related emotional impacts and more severe impacts overall if they reported having more types of tangible experiences 
(i.e., with past evacuation, property damage, financial loss). However, many respondents reported that they had emotional impacts or moderate to severe overall impacts despite not having experienced any of these tangible experiences. This suggests that classifying people as having experienced a hurricane using only these types of tangible measures-which are among items that researchers commonly use to measure people's experience-may miss people who have experienced hurricanes (or other hazards) in other ways.

More fundamentally, these results suggest that people's intangible experiences should be further conceptualized and investigated to better understand how people interpret, synthesize, and make meaning from a hazard that affects them. For instance, as investigated by Demuth (2015) in the context of tornadoes, other intangible experiences in addition to those measured here may include intrusive thoughts and feelings, life disruption, or other aspects. These intangible impacts could result from an individual's direct experience with a hazard, or they could be vicariously experienced via hazards that affect known others as well as unknown others (e.g., observed via news media). Further conceptualizing intangible and other experiences can have important theoretical implications for understanding how people plan for, judge, and respond to future risks.

The results of the parallel mediation analyses provide empirical insight into theorized processes by which different past hurricane experiences exert an effect on evacuation intention through mediators of risk perception and efficacy beliefs. Although the sizes of the indirect effects are modest, the analyses highlight the different ways that experience can have an effect through different intervening variables.

One finding of interest is that, other than past evacuation experience, each of the different past hurricane experiences operated through only certain intervening variables to influence evacuation intention. For instance, people's experience with past property damage decreased their beliefs that evacuating is an effective way to reduce harm (response efficacy). This perception makes some people less likely to evacuate, perhaps because they believe they can better protect their property by staying, or because they anticipate a threat to property more than a threat to life. Also, people's past hurricane-related experience with emotional impacts affected their perceptions of fear, worry, dread, and anxiety (negative affect) as well as their beliefs in their ability to do what would be needed to evacuate (self efficacy). These results illustrate the different effects that different past hurricane experiences can have as well as the conceptual correspondence between a specific aspect of experience and the mediator(s) it affects (Weinstein 1989).

Another important finding is that experience with hurricane-related emotional impacts had indirect effects that worked in opposite directions, enhancing evacuation intentions through heightened negative affect but dampening intentions through lower self efficacy. In other words, these mediated relationships emerged in the absence of a total effect, that is, even without a statistically significant relationship between experience and evacuation intent. This, understandably, is counterintuitive; a significant total effect (i.e., significant relationship between $X$ and $Y$ ) has long been considered as the first in a series of requirements, known as the "causal steps approach," for an effect to be mediated (Hayes 2009, 2013). This erroneous belief about mediated relationships is increasingly being abandoned as revealed otherwise by methodologists and by empirical research-including the findings shown here that certain mechanisms can be operating for some people but that the effects may be masked by other effects, especially those that operate in competing directions.

The mediation analyses also illustrate that all of the aspects of past hurricane experiences measured here, other than property damage, enhanced evacuation intention through heightening negative affect (fear, worry, dread, anxiety). Risk scholars have suggested that past experiences are tagged with affect and that people automatically recall and draw on these affective associations when judging a future risk (Epstein 1994; Slovic et al. 2004); this mental shortcut has been termed the "affect heuristic." The results here not only demonstrate this link but also show that it occurs for multiple, different experiences. Given that affect was measured here as it pertained to a simulated hurricane risk context, the experience-induced negative emotions that one may feel during a real hurricane threat may be even stronger. These results suggest the need to give more credence to the role that affect (negative or positive) plays for weather risks and to better understand the role of experience in influencing it.

Relatedly, the analyses reveal there is limited evidence that past experience, other than past evacuation experience, influences behavior through cognitive risk perception, measured here as respondents' chance of being affected by the hurricane and the harm it would cause. These measures may be less meaningful for our sample of coastal residents because most of them live in evacuation zones, which means that they have an increased chance of being affected and harmed by a hurricane. Thus, in future work, it may be valuable to examine measures of cognitive risk perception that focus on more specific and personalized impacts (Morss 
et al. 2016b) or on other dimensions. For example, Trumbo et al. (2016) developed and validated a general (not event specific) scale of hurricane risk perception, where the cognitive dimension is measured as concrete, extreme, and observable impacts (e.g., catastrophic destruction, widespread death).

Last, the mediation analyses revealed that past evacuation experience indirectly increased evacuation intention by enhancing all the dimensions of risk perception and efficacy beliefs. Having experience evacuating can provide concrete knowledge about what that response behavior entails-what Riad et al. (1999) term an "evacuation repertoire," where people know how to act and what to do-as well as about the utility of the action. This may explain why past evacuation experience is mediated through self efficacy and response efficacy. Past evacuation experience also influenced evacuation intentions directly, though, suggesting that other intervening variables are at play that were not explored here. Other mediators could include situational motivations and/or barriers (Huang et al. 2012; Lazo et al. 2015; Lindell and Perry 2012); attitudes toward the behavior (e.g., Fishbein and Ajzen 2010); or other, unknown factors that might be revealed through qualitative inquiry with people who have evacuated. For some people, though, past evacuation experience may represent either a general risk aversion or a tendency to evacuate for any hurricane threat. These factors represent a different process, one where an individual's dispositions toward risk are the factors that could affect whether one has evacuated in the past and their judgments and responses to future risks. Future research that explores other possible mediators of past evacuation experience, and research that differentiates the effects of individuals' characteristics from the effects of their specific experiences, would both help better understand how past evacuation experience influences future behaviors.

The research conducted here provides a foundation for future work, in addition to that already mentioned. For risk communication practice, understanding the mechanisms by which different past experiences can influence evacuation intentions can help identify where risk communication interventions could be developed to encourage desired behavioral responses. For instance, for people with past property damage who might consider evacuating to be a less effective response, risk messages could emphasize that evacuation reduces risks to one's safety and well-being, which are paramount. Or, for people with past emotional impacts who have less confidence in their evacuation abilities, messages could be designed to promote self efficacy by providing detailed information about how and when to evacuate and where they can easily seek help if needed (e.g., Duval and Mulilis 1999). Research would be required to evaluate and refine the specific message content and to determine which sources (e.g., local public officials, faith-based leaders, broadcast meteorologists) are most trusted and credible for message delivery.

In addition, research should be done to investigate how the mediated relationships examined here might vary based on respondents' characteristics (e.g., age, length of residence) or other attitudes (i.e., moderated mediation; see Hayes 2013), as well as how results might vary based on other populations and other hazardous weather events. Finally, we focused here on past experience as the antecedent variable of interest because of its prevalence in the risk literature and to the different aspects of experience that can be separately examined. Future work should also investigate the mechanisms by which other antecedent variables, including risk messages and respondents' characteristics (e.g., cultural worldviews), affect responses to weather risks. The amalgam of such research efforts can have important implications for helping better understand and protect populations at risk of hazardous weather.

Acknowledgments. Thank you to three anonymous reviewers and to James Done for helpful comments on the manuscript. Also, thank you to Betty Morrow, H. Dan O'Hair, Claude Miller, Matthew Jensen, Ann Bostrom, and members of the project's Expert Advisory Group for their contributions to the survey design. This research was supported by National Science Foundation Award 0838702, which was jointly funded by the National Oceanic and Atmospheric Administration. Views and opinions in this paper are those of the authors.

\section{APPENDIX}

\section{Factor Analysis of Risk Perception and Efficacy Beliefs}

Presented in the tables are the survey questions and items used to measure the dimensions of risk perception (Table A1) and efficacy beliefs (Table A2) as they pertained to the Hurricane Julia scenario. The items were randomized during survey implementation. The mean and standard deviation for each item and the factor analysis results also are presented. Common factor analysis was conducted using an oblique (promax) oblique rotation to allow the resulting factors to be correlated. For all analyses, $n=255$. 
TABLE A1. Risk perception survey measures, factor loadings, and item statistics. Items that strongly load onto each factor are shown in boldface type. Survey question with the cognitive risk perception items: "Agree or disagree? Statements about the probability and severity of Hurricane Julia based on the information you received." (Response options: Very strongly disagree $=1$, Strongly disagree $=2$, Disagree $=3$, Neither agree nor disagree $=4$, Agree $=5$, Strongly agree $=6$, Very strongly agree $=7$ ). Survey question with the affective risk perception items: "If presented with this information about Hurricane Julia, indicate how you would feel along a scale between each of the following sets of words. I would feel..." (Response options: seven-point semantic differential with the shown paired, opposite adjectives anchoring each end).

\begin{tabular}{|c|c|c|c|c|}
\hline \multirow[b]{3}{*}{ Survey item } & \multicolumn{2}{|c|}{ Factor loadings } & \multirow{2}{*}{\multicolumn{2}{|c|}{ Item statistics }} \\
\hline & \multirow{2}{*}{$\begin{array}{c}\text { Factor } 1 \\
\text { (Cognitive risk perception) }\end{array}$} & \multirow{2}{*}{$\begin{array}{c}\text { Factor } 2 \\
\text { (Affective risk perception) }\end{array}$} & & \\
\hline & & & Mean & $\overline{\text { Std Dev }}$ \\
\hline $\begin{array}{l}\text { It is likely that Hurricane Julia will hit my } \\
\text { residence }\end{array}$ & 0.80 & -0.06 & 5.3 & 1.1 \\
\hline $\begin{array}{l}\text { If I do not evacuate, I am likely to be personally } \\
\text { affected by Hurricane Julia }\end{array}$ & 0.78 & 0.02 & 5.3 & 1.3 \\
\hline $\begin{array}{l}\text { I do not currently think Hurricane Julia presents } \\
\text { any threat to me (reverse scored) }\end{array}$ & 0.49 & 0.01 & 5.6 & 1.4 \\
\hline $\begin{array}{l}\text { I believe that the danger posed by Hurricane } \\
\text { Julia is considerable }\end{array}$ & 0.83 & 0.03 & 5.7 & 1.1 \\
\hline $\begin{array}{l}\text { I think the potential impact from Hurricane Julia } \\
\text { is significant }\end{array}$ & 0.87 & -0.03 & 5.6 & 1.1 \\
\hline $\begin{array}{l}\text { I believe that the damages from Hurricane Julia } \\
\text { will be devastating }\end{array}$ & 0.70 & 0.03 & 5.1 & 1.4 \\
\hline Assured-worried & 0.01 & 0.82 & 4.7 & 1.7 \\
\hline Fearless-fearful & 0.04 & 0.75 & 4.3 & 1.5 \\
\hline At ease-anxious & 0.01 & 0.84 & 4.6 & 1.6 \\
\hline Confident-dread & -0.06 & 0.69 & 3.8 & 1.6 \\
\hline$\%$ of total variance explained & $42.0 \%$ & $24.1 \%$ & & \\
\hline Cronbach's $\alpha$ & 0.87 & 0.86 & & \\
\hline
\end{tabular}

TABLE A2. Efficacy belief survey measures, factor loadings, and item statistics. Items that strongly load onto each factor are shown in boldface type. Survey question with all efficacy items: "Agree or disagree? Statements about your ability to evacuate in response to the threat of Hurricane Julia or how effective evacuation would be" (Response options: Very strongly disagree $=1$, Strongly disagree $=2$, Disagree $=3$, Neither agree nor disagree $=4$, Agree $=5$, Strongly agree $=6$, Very strongly agree $=7$ )

\begin{tabular}{lcccc}
\hline \hline & \multicolumn{2}{c}{ Factor loadings } & Item statistics \\
\cline { 2 - 4 } Survey item & Factor 1 (Self efficacy) & Factor 2 (Response efficacy) & Mean & Std Dev \\
\hline Evacuation would be effective to prevent injury or death & -0.01 & $\mathbf{0 . 9 4}$ & 5.4 \\
If I evacuate, I am less likely to get injured or die & -0.03 & $\mathbf{0 . 8 6}$ & 1.3 \\
Evacuation would be effective to reduce suffering & 0.21 & $\mathbf{0 . 6 8}$ & 5.4 \\
I would be able to do what is needed in order to evacuate & $\mathbf{0 . 8 6}$ & 0.07 & 5.3 \\
I would be capable of effectively evacuating & $\mathbf{0 . 9 1}$ & 0.00 & 5.6 \\
I would be able to take the time to prepare and evacuate & $\mathbf{0 . 7 4}$ & 0.03 & 5.5 \\
\% of total variance explained & $69.9 \%$ & $13.4 \%$ & 5.4 \\
Cronbach's $\alpha$ & 0.89 & 0.90 & 1.2 \\
\hline
\end{tabular}

\section{REFERENCES}

Arlikatti, S., M. Lindell, C. S. Prater, and Y. Zhang, 2006: Risk area accuracy and hurricane evacuation expectations of coastal resident. Environ. Behav., 38, 226-247, doi:10.1177/ 0013916505277603.

Baker, E. J., 1991: Hurricane evacuation behavior. Int. J. Mass Emerg. Disasters, 9, 287-310.

Baraldi, A. N., and C. K. Enders, 2010: An introduction to modern missing data analyses. J. Sch. Psychol., 48, 5-37, doi:10.1016/ j.jsp.2009.10.001.

Barnett, J. J., and G. M. Breakwell, 2001: Risk perception and experience: Hazard personality profiles and individual differences. Risk Anal., 21, 171-178, doi:10.1111/0272-4332.211099.
Burnside, R., D. Shondell Miller, and J. D. Rivera, 2007: The impact of information and risk perception on the hurricane evacuation decision-making of greater New Orleans residents. Sociol. Spectr., 27, 727-740, doi:10.1080/ 02732170701534226.

Demuth, J. L., 2015: Developing a valid scale of past tornado experiences. Ph.D. dissertation, Colorado State University, 194 pp. [Available online at https://dspace.library.colostate.edu/ handle/10217/170377.]

Duval, T. S., and J.-P. Mulilis, 1999: A Person-Relative-to-Event (PrE) approach to negative threat appeals and earthquake preparedness: A field study. J. Appl. Soc. Psychol., 29, 495516, doi:10.1111/j.1559-1816.1999.tb01398.x. 
Epstein, S., 1994: Integration of the cognitive and the psychodynamic unconscious. Amer. Psychol., 49, 709-724, doi:10.1037/ 0003-066X.49.8.709.

Fishbein, M., and I. Ajzen, 2010: Predicting and Changing Behavior: The Reasoned Action Approach. Psychology Press, $538 \mathrm{pp}$.

Frick, R. W., 1998: Interpreting statistical testing: Process and propensity, not population and random sampling. Behav. Res. Methods Instrum. Comput., 30, 527-535, doi:10.3758/ BF03200686.

Greenberg, M., C. Haas, A. Cox Jr., K. Lowrie, K. McComas, and W. North, 2012: Ten most important accomplishments in risk analysis, 1980-2010. Risk Anal., 32, 771-781, doi:10.1111/ j.1539-6924.2012.01817.x.

Grothmann, T., and F. Reusswig, 2006: People at risk of flooding: Why some residents take precautionary action while others do not. Nat. Hazards, 38, 101-120, doi:10.1007/s11069-005-8604-6.

Harrell, F. E., Jr., 2001: Regression Modeling Strategies: With Applications to Linear Models, Logistic Regression, and Survival Analysis. Springer-Verlag, $582 \mathrm{pp}$.

Hayes, A. F., 2005: Statistical Methods for Communication Science. Routledge, 517 pp.

_ 2009: Beyond Baron and Kenny: Statistical mediation analysis in the new millennium. Commun. Monogr., 76, 408-420, doi:10.1080/03637750903310360.

_ - 2013: Introduction to Mediation, Moderation, and Conditional Process Analysis. Guilford Press, 507 pp.

— 2016: The PROCESS macro for SPSS and SAS. Accessed 5 July 2014. [Available online at http://www.processmacro. org/index.html.]

Huang, S.-K., M. K. Lindell, C. S. Prater, H. Wu, and L. K. Siebeneck, 2012: Household evacuation decision making in response to Hurricane Ike. Nat. Hazards Rev., 13, 283-296, doi:10.1061/(ASCE)NH.1527-6996.0000074.

,$- \ldots$, and $\_, 2016$ : Who leaves and who stays? A review and statistical meta-analysis of hurricane evacuation studies. Environ. Behav., doi:10.1177/0013916515578485, in press.

Kellens, W., T. Terpstra, and P. De Maeyer, 2013: Perception and communication of flood risks: A systematic review of empirical research. Risk Anal., 33, 24-49, doi:10.1111/ j.1539-6924.2012.01844.x.

Kim, J. O., and C. W. Mueller, 1981: Standardized and unstandardized coefficients in causal analysis: An expository note. Sociol. Methods Res., 4, 428-438, doi:10.1177/ 004912417600400402.

Lazo, J. K., D. M. Waldman, B. H. Morrow, and J. A. Thatcher, 2010: Household evacuation decision making and the benefits of improved hurricane forecasting: Developing a framework for assessment. Wea. Forecasting, 25, 207-219, doi:10.1175/ 2009WAF2222310.1.

_ A. Bostrom, R. E. Morss, J. L. Demuth, and H. Lazrus, 2015: Factors affecting hurricane evacuation intentions. Risk Anal., 35, 1837-1857, doi:10.1111/risa.12407.

Lindell, M. K., 2012: Response to environmental disasters. The Oxford Handbook of Environmental and Conservation Psychology, S. D. Clayton, Ed., Oxford University Press, 391-412.

—_ and S. N. Hwang, 2008: Households' perceived personal risk and responses in a multihazard environment. Risk Anal., 28, 539-556, doi:10.1111/j.1539-6924.2008.01032.x.

— Model: Theoretical modifications and additional evidence. Risk Anal., 32, 616-632, doi:10.1111/j.1539-6924.2011.01647.x.
— C. J. Lu, and C. S. Prater, 2005: Household decision making and evacuation in response to Hurricane Lili. Nat. Hazards Rev., 6, 171-179, doi:10.1061/(ASCE)1527-6988(2005)6:4(171).

Matyas, C., S. Srinivasan, I. Cahyanto, B. Thapa, L. PenningtonGray, and J. Villega, 2011: Risk perception and evacuation decisions of Florida tourists under hurricane threats: A stated preference analysis. Nat. Hazards, 59, 871-890, doi:10.1007/ s11069-011-9801-0.

McNeeley, S. M., and H. Lazrus, 2014: The cultural theory of risk for climate change adaptation. Wea. Climate Soc., 6, 506-519, doi:10.1175/WCAS-D-13-00027.1.

Meyer, R., K. Broad, B. Orlove, and N. Petrovic, 2013: Dynamic simulation as an approach to understanding hurricane risk response: Insights from Stormview lab. Risk Anal., 33, 15321552, doi:10.1111/j.1539-6924.2012.01935.x.

Morss, R. E., J. L. Demuth, J. K. Lazo, K. Dickinson, H. Lazrus, and B. H. Morrow, 2016a: Understanding public hurricane evacuation decisions and responses to hurricane risk messages. Wea. Forecasting, 31, 395-417, doi:10.1175/WAF-D-15-0066.1.

— K. J. Mulder, J. K. Lazo, and J. L. Demuth, 2016b: How do people perceive, understand, and anticipate responding to flash flood risks and warnings? Results from a public survey in Boulder, Colorado, USA. J. Hydrol., doi:10.1016/ j.jhydrol.2015.11.047, in press.

Norris, F. H., T. Smith, and K. Kaniasty, 1999: Revisiting the experience-behavior hypothesis: The effects of Hurricane Hugo on hazard preparedness and other self-protective acts. Basic Appl. Soc. Psych., 21, 37-47.

Peacock, W. P., S. D. Brody, and W. Highfield, 2005: Hurricane risk perceptions among Florida's single family homeowners. Landscape Urban Plann., 73, 120-135, doi:10.1016/j.landurbplan.2004.11.004.

Preacher, K. J., and A. F. Hayes, 2008: Asymptotic and resampling strategies for assessing and comparing indirect effects in multiple mediator models. Behav. Res. Methods, 40, 879-891, doi:10.3758/BRM.40.3.879.

— , and K. Kelly, 2011: Effect size measures for mediation models: Quantitative strategies for communicating indirect effects. Psychol. Methods, 16, 93-115, doi:10.1037/a0022658.

Renn, O., 2008: Review of psychological, social and cultural factors of risk perception. Risk Governance: Coping with Uncertainty in a Complex World, O. Renn, Ed., Earthscan, 98-148.

Riad, J. K., F. N. Norris, and R. B. Ruback, 1999: Predicting evacuation in two major disasters: Risk perception, social influence, and access to resources. J. Appl. Soc. Psychol., 29, 918-934, doi:10.1111/j.1559-1816.1999.tb00132.x.

Rogers, R. W., 1975: A protection motivation theory of fear appeals and attitude change. J. Psych., 91, 93-114, doi:10.1080/ 00223980.1975.9915803.

__ 1983: Cognitive and physiological processes in fear appeals and attitude change: A revised theory of protection motivation. Social Psychophysiology: A Sourcebook, J. Cacioppo and R. Petty, Eds., Guilford Press, 153-176.

Slovic, P., 2010: The Feeling of Risk: New Perspectives on Risk Perception. Earthscan, 425 pp.

—, M. L. Finucane, E. Peters, and D. G. MacGregor, 2004: Risk as analysis and risk as feelings: Some thoughts about affect, reason, risk, and rationality. Risk Anal., 24, 311-322, doi:10.1111/ j.0272-4332.2004.00433.x.

Tansey, J., and T. O'Riordan, 1999: Cultural theory and risk: A review. Health Risk Soc., 1, 71-90, doi:10.1080/13698579908407008.

Trumbo, C., M. Lueck, H. Marlatt, and L. Peek, 2011: The effect of proximity to Hurricanes Katrina and Rita on subsequent 
hurricane outlook and optimistic bias. Risk Anal., 31, 19071918, doi:10.1111/j.1539-6924.2011.01633.x.

, L. Peek, M. Meyer, H. Marlatt, E. Gruntfest, B. McNoldy, and W. Schubert, 2016: A cognitive-affective scale for hurricane risk perception. Risk Anal., doi:10.1111/risa.12575, in press.

Wachinger, G., O. Renn, C. Begg, and C. Kuhlicke, 2013: The risk perception paradox-Implications for governance and communication of natural hazards. Risk Anal., 33, 1049-1065, doi:10.1111/j.1539-6924.2012.01942.x.
Weinstein, N. D., 1989: Effects of personal experience on self-protective behavior. Psychol. Bull., 105, 31-50, doi:10.1037/0033-2909.105.1.31. 1993: Testing four competing theories of health-protective behavior. Health Psychol., 12, 324-333, doi:10.1037/ 0278-6133.12.4.324.

Zaalberg, R., C. Midden, A. Meijnders, and T. McCalley, 2009: Prevention, adaptation, and threat denial: Flooding experiences in the Netherlands. Risk Anal., 29, 1759-1778, doi:10.1111/j.1539-6924.2009.01316.x. 